\title{
SÍNDROME DO TÚNEL DO CARPO: UMA REVISÃO BIBLIOGRÁFICA
}

\author{
CARPAL TUNNEL SYNDROME: A LITERATURE REVIEW
}

\author{
Liliane Ferreira Alexandre', Layra da Silva Alves', Inês Raquel Alves da Silva Rosárioº, Frederico Miranda \\ Pessanha', Marlana Ribeiro Monteiro² \\ 1Acadêmico no curso de medicina na Faculdade de Medicina de Campos-RJ \\ 2Professora da Faculdade de Medicina de Campos- RJ \\ Faculdade de Medicina de Campos, Avenida Alberto Torres, 217, Centro Campos dos Goytacazes- RJ, CEP \\ 28035-581. Telefone (22) 2101-2929 \\ Endereço para correspondência: Fundação Benedito Pereira Nunes. Avenida Alberto Torres, 217, Centro \\ Campos dos Goytacazes- RJ, (22) 98813-0958, email: bra2223@gmail.com
}

\section{RESUMO}

A síndrome do túnel do carpo é a síndrome mais comum de encarceramento do nervo periférico mundialmente. Os achados do exame físico e os sintomas clínicos em pacientes com essa síndrome são amplamente reconhecidos e há diversos tratamentos, desde opções cirúrgicas e não cirúrgicas. Apesar dessas vantagens, há uma escassez de evidências sobre as melhores abordagens para avaliação desta patologia e para orientar as decisões de tratamento. Embora o melhor meio de integrar aspectos clínicos, funcionais e informações anatômicas para a seleção de opções de tratamento ainda não foram identificadas, os pacientes podem ser diagnosticados rapidamente e respondem bem ao tratamento. A alta prevalência da síndrome do túnel do carpo, seus efeitos na qualidade de vida e o custo que a carga da doença gera para os sistemas de saúde tornam importante identificar as prioridades de pesquisa.

Palavras chave: síndrome do túnel do carpo, nervo periférico

\begin{abstract}
Carpal tunnel syndrome is the most common peripheral nerve entrapment syndrome worldwide. The clinical symptoms and physical examination findings in patients with this syndrome are recognised widely and various treatments exist, including surgical and non-surgical options. Despite these advantages, there is a paucity of evidence about the best approaches for assessment of carpal tunnel syndrome and to guide treatment decisions. Although the best means of integrating clinical, functional, and anatomical information for selecting treatment choices has not yet been identified, patients can be diagnosed quickly and respond well to treatment. The high prevalence of carpal tunnel syndrome, its effects on quality of life, and the cost that disease burden generates to health systems make it important to identify the research priorities. Keywords: carpal tunnel syndrome; peripheral nerve.
\end{abstract}




\section{INTRODUÇÃO}

A síndrome do túnel do carpo (STC) é uma neuropatia de aprisionamento e, assim como tal, se caracteriza por ser um distúrbio que reduz a função da musculatura da mão devido a compressão e/ou tração do nervo mediano ao nível do punho, podendo também afetar a sensibilidade da região, principalmente do lado palmar. A STC representa a mais frequente das síndromes compressivas e é um dos transtornos das extremidades superiores que mais geram custos e incapacidades. (DE OLIVEIRAFILHO; DE OLIVEIRA, 2017) (HUISSTEDE et al., 2018)

James Paget, foi o primeiro a descrever a STC, através de um caso de compressão do nervo mediano reportado em consequência de uma fratura do rádio distal. Todavia, somente a partir da década de 50, os trabalhos de George S. Phalen estabeleceram os princípios da STC.

Esta síndrome possui pico de incidência entre 40 e 59 anos e sua prevalência é estimada entre 4 e $5 \%$ da população. Outrossim, estudos transversais vêm demonstrando prevalência de $9,2 \%$ nas mulheres e $0,6 \%$ nos homens.

Os sinais e os sintomas clínicos mais comuns desta patologia são: dor, parestesia e dormência no território de sensibilidade do nervo mediano (particularmente no indicador, médio, dedo polegar e face radial do dedo anular), podendo haver piora noturna dos sintomas.

\section{OBJETIVOS}

Realizar uma revisão bibliográfica para estabelecer um conhecimento geral acerca da Síndrome do Túnel do Carpo e abordar fatores de risco e causas, características clínicas, diagnóstico, diagnóstico diferencial e tratamento.

\section{MÉTODOS}

O método utilizado nesse estudo foi a revisão bibliográfica e estudo descritivo. Obteve-se material a partir de artigos científicos. As palavraschave utilizadas para pesquisa foram utilizadas na língua portuguesa e inglesa. $O$ descritor utilizado para a pesquisa foi: túnel do carpo, nervo mediano, nervo periférico, anatomia.

\section{REVISÃO BIBLIOGRÁFICA Anatomia}

O túnel do carpo é um túnel osteofibroso inextensível definido como o espaço localizado entre a canaleta carpiana, que compõe o fundo e o retináculo dos flexores, que constitui o teto. É delimitado na borda ulnar pelo hâmulo do hamato, o pisiforme e o piramidal e na borda radial pelo escafóide, o tendão do flexor radial do carpo e o trapézio. A base é formada pela cápsula e os ligamentos radiocárpicos anteriores recobrem as porções subjacentes do escafoide, do semilunar, do capitato, do hamato, do trapézio e do trapezóide.

\section{Conteúdo}

O conteúdo do túnel é constituído pelo nervo mediano e por nove tendões: quatro tendões do músculo flexor profundo dos dedos, quatro tendões do músculo flexor superficial dos dedos (FSD), e um tendão do músculo flexor longo do polegar (FLP). Na região palmar, o nervo mediano se divide em seus ramos distais: ramo motor, em geral único, que inerva os músculos tenares, oponente do polegar, abdutor e flexor curto do polegar; ramos motores que seguem para o primeiro e segundo músculos lumbricais; e ramos digitais palmares sensitivos que inervam a pele do segundo, terceiro e metade lateral do quarto dedo.

Na entrada do túnel, o nervo mediano está situado dorsalmente em relação ao palmar longo (PL) ou entre o flexor radial do carpo (FRC) e o PL. Em posição neutra do punho, o nervo mediano está em frente ao FSD do indicador, entre o FLP e o FSD do indicador ou em frente ao FSD do dedo médio. $\mathrm{Na}$ parte distal do túnel o nervo mediano se divide em seis ramos: o ramo motor ou tenar, três nervos digitais palmares próprios (radial e ulnar do polegare radial do indicador) e os nervos digitais palmares comuns do segundo e do terceiro espaços. $O$ ramo tenar passa através de um túnel separado antes de entrar nos músculos tenares em $56 \%$ dos casos.

\section{Territórios de inervação do nervo mediano na mão}

Sobre o plano motor, o nervo mediano inerva classicamente os músculos de oposição, o abdutor curto do polegar, oponente do polegar e feixe superficial do flexor curto do polegar e os dois primeiros músculos lumbricais.

O território sensitivo do nervo mediano ocupa a metade radial do dedo anular e a face palmar de três dedos radiais. Na face dorsal, ele compreende as duas últimas falanges dos três primeiros dedos e a metade radial do quarto. Quanto mais proximal o ramo cutâneo palmar acima do 
ligamento anterior, mais explicada é a falta de participação na sintomatologia da zona tenariana.

\section{Fatores de risco e causas}

Fatores de risco suspeitos de síndrome do túnel do carpo (STC) incluem diabetes mellitus, menopausa, hipotireoidismo, obesidade, artrite e gravidez. Como o hipotireoidismo, a menopausa e a gravidez são fatores de risco, existe forte suspeita de que alterações hormonais podem ser o causador; no entanto, não existem evidências para apoiar esta hipótese. Gravidez provavelmente aumenta o risco de STC por uma combinação de edema e alterações hormonais; dados epidemiológicos mostram que a incidência de STC relacionada à gravidez é alta ( $7-43 \%$ quando diagnosticados eletrofisiologicamente e 31-62\% quando diagnosticado com base na história e apenas estudos de exame clínico). Início agudo com sintomas marcantes e fraqueza motora não é infrequente, e os sintomas frequentemente persistem após o parto.

Fortes evidências suportam diabetes tipo 1 e tipo 2 como fatores de risco para a STC, da mesma forma, o excesso de peso aumenta o risco de STC em 1,5 vezes e obesidade aumenta o risco em duas vezes. No entanto, não há comprovação para um mecanismo específico pelo qual a diabetes ou obesidade aumenta o risco de STC.

A associação entre computador, teclado ou mouse e STC ainda é controverso. Evidências disponíveis sugerem que, no máximo, uso excessivo de computadores é um fator de risco menor, provavelmente resultante do estresse mecânico do nervo causado por contato com tendões circundantes excessivamente usados.

\section{Características clínicas}

A síndrome é caracterizada inicialmente por parestesias noturnas intermitentes e disestesias que aumentam em frequência e ocorrem durante as horas de vigília. Em seguida, perda de sensibilidade desenvolve-se juntamente com fraqueza e atrofia muscular mais tarde no curso da doença, que resulta de extensa degeneração axonal. Esta sequência de sintomas é bastante típica, raramente ocorrendo em outros distúrbios além da referida STC.

As manifestações clínicas iniciais são queimação, dor, formigamento e dormência na mão, geralmente de evolução insidiosa, acometendo território de inervação do nervo mediano. De forma clássica, os sintomas acentuamse no período noturno, por vezes de forma intensa, chegando a despertar o paciente. Alguns autores consideram essa manifestação como um sinal da doença que sugere o diagnóstico. Movimentos repetitivos com o punho como costurar, escrever dentre outros podem exacerbar os sintomas. A progressão da doença pode resultar em redução da sensibilidade na distribuição do nervo mediano e diminuição de força e em casos graves, podem se espalhar proximalmente ao antebraço, parte superior do braço e às vezes ombro.

Quando os portadores da referida síndrome são perguntados especificamente sobre localização da dor e os sintomas sensoriais, eles geralmente relatam que os sintomas nas regiões proximais são caracterizados por dor e não por dormência, formigamento ou outras anormalidades sensoriais. Por muitos anos, critérios diagnósticos sensoriais na literatura foram limitados a sintomas que ocorrem no nervo mediano no território da mão. No entanto, na prática clínica, mais critérios sensoriais foram utilizados, não limitando os sintomas aos primeiros três dígitos, mas incluindo todo a superfície palmar. Esse padrão, constantemente observado de anormalidades, pode ser secundário a um mecanismo do sistema nervoso central (envolvimento ulnar simultâneo ou sensibilização central respectivamente), ou ambos. Evidências sugerem que os sintomas limitados para os três primeiros dígitos podem indicar comprometimento mais grave do nervo mediano, isto é, distribuição dos sintomas na área inervada pelo nervo mediano é associada a alterações mais graves na condução nervosa. Assim, a distribuição dos sintomas deve ser definida com a maior precisão possível e fortemente considerada ao decidir a estratégia de tratamento e determinar prognóstico.

\section{Diagnóstico}

Em primeiro lugar, não existe um padrãoouro para o diagnóstico positivo da STC. Uma história clínica cuidadosa pode nunca estabelecer a causa da mesma no paciente, enquanto que a história bem descrita em combinação com o exame físico consistente na STC na maioria dos casos pode levar ao diagnóstico correto. Apesar dessa patologia continuar a ser um diagnóstico clínico, o teste eletrodiagnóstico substituiu um exame físico 
cuidadoso em muitas práticas. A história clínica e o exame físico, incluindo testes provocativos, são mais facilmente realizados do que os estudos de eletrodiagnóstico, e são as ferramentas de diagnóstico mais adequadas no cenário ambulatorial.

A abordagem clínica em paciente com acroparestesia da mão inclui certas etapas como discutir o diagnóstico no interrogatório, nos testes provocativos, na análise de eventuais patologias associadas e diagnóstico diferencial; determinar a etiologia; julgar a oportunidade de fazer exames complementares, em primeiro lugar o exame eletroneuromiográfico (ENMG); propor o tratamento adaptado ao estado de gravidade, à etiologia, ao local e ao contexto de atividade.

Pacientes com STC frequentemente apresentam queixa de dormência e formigamento em seus dedos. Uma avaliação sensorial minuciosa é a garantia no exame inicial. É aconselhável sempre realizar a avaliação da sensibilidade antes do teste provocativo, pois os testes provocativos podem alterar a sensibilidade dos pacientes. No entanto, os testes mais comuns utilizados para avaliar sensibilidade são estáticos ou movendo-se a discriminação de dois pontos, o teste de monofilamentos de Semmes-Weinstein e vibrometria. Compreender os sistemas de receptores de fibras nervosas e seu papel na sensação são necessários para avaliar o que realmente está sendo testado pelos vários testes de sensibilidade.

O teste de sensibilidade é conceitualmente dividido em testes de densidade de inervação e testes limítrofes. A discriminação estática e móvel de dois pontos são testes de densidade de inervação. A discriminação estática de dois pontos mede lentamente adaptação de receptores de fibra enquanto medidas de discriminação de dois pontos móveis se adaptam rapidamente às fibras. Os testes de densidade de inervação medem a inervação de múltiplos receptores periféricos e são dependentes da integração cortical de impulsos periféricos porque um estímulo pode ser percebido normalmente na presença de algumas fibras periféricas intactas, compressão leve ou mesmo moderada de um nervo periférico podem não produzir qualquer alteração em um teste de densidade de inervação. Testes limítrofes, como monofilamentos de Semmes-Weinstein e vibrometria, avaliam fibras nervosas que inervam um único receptor ou grupo de células receptoras. Estes são mais propensos a mostrar uma mudança gradual e progressiva em valor à medida que mais e mais fibras nervosas são afetadas, como na compressão nervosa. O teste limítrofe é o método preferido para avaliar a sensibilidade da mão no STC.

\section{Teste provocativo}

Muitos testes provocativos foram descritos para auxiliar no diagnóstico da STC. Todos são baseados em provocar um nervo mediano já comprometido a fim de exacerbar os sintomas de dormência, dor e parestesias. Uma série de testes provocativos pode estar presente na STC. Desses testes, o de Phalen é considerado um dos mais sensíveis, sendo positivo em cerca de $80 \%$ dos pacientes. Os três mais comuns testes provocativos utilizados são a flexão do punho teste, conhecido também como teste de Phalen, a percussão do nervo mediano teste de Tinel e teste de compressão do nervo mediano. $O$ teste do torniquete, também um teste provocativo, raramente é usado por causa de sua alta taxa de falsos positivos.

Um dos testes mais universalmente utilizados é o teste de flexão do punho introduzido por Phalen em 1951. Este teste foi originalmente realizado mantendo os antebraços eretos, com os cotovelos apoiados na mesa de exame. Os pulsos devem ser mantidos em flexão com a ajuda da gravidade por 30 a 60 segundos. O teste é melhor realizado eliminando a flexão do cotovelo que pode produzir sintomas no dedo mínimo por causa da compressão do nervo ulnar no túnel cubital. Dormência ou formigamento na distribuição do nervo mediano é considerado um teste positivo. Nesta posição, acredita-se que o nervo mediano é comprimido entre a borda proximal do ligamento carpal transverso e os tendões flexores subjacentes. Este teste é menos útil se houver movimento limitado do pulso ou em casos de compressão grave do nervo mediano. A extensão do punho estreita o canal do carpo e aumenta mais a pressão dentro do canal do que a flexão do punho. Essa posição também pode exacerbar os sintomas da STC e formar a base de outro teste provocativo, a manobra reversa de Phalen. Phalen relatou que entre $74 \%$ e $80 \%$ de seus pacientes com STC tiveram testes positivos de flexão do punho; no entanto, parte de sua crença no diagnóstico da STC foi baseada em uma resposta 
positiva teste. A sensibilidade é de $67 \%$ a $83 \%$ e a especificidade é de $47 \%$ a $100 \%$.

O sinal de Tinel ou a percussão do nervo mediano são realizados tocando suavemente ao longo do nervo mediano no punho de proximal a distal. Uma resposta positiva é registrada se o paciente percebe formigamento na distribuição do nervo mediano. $O$ examinador deve realizar este teste gentilmente porque o uso de muita força pode produzir parestesias em um nervo mediano normal. A sensibilidade é de $26 \%$ a $79 \%$ e a especificidade é de $40 \%$ a $100 \%$.

\section{Exame eletroneuromiográfico}

Compreende uma etapa de estímulo e uma etapa de detecção. É um exame bilateral. A etapa estímulo-detecção permite estudar a condução nervosa sensitiva e motora do nervo mediano e destaca o abrandamento eletivo na passagem do túnel do carpo. Permite igualmente a análise da amplitude e da duração das respostas motoras e sensitivas. Essa exploração é completada por uma medida da condução nervosa do nervo ulnar homolateral e por estudos do lado contralateral. A anomalia elétrica mais precoce e mais sensível é uma diminuição da velocidade de condução sensitiva entre a palma da mão e os dedos e o punho. É aceito uma velocidade transtúnel do mediano $<45 \mathrm{~m} / \mathrm{s}$ patológica, por uma normal $\geq$ $50 \mathrm{~m} / \mathrm{s}$. Esse exame é operador-dependente, a temperatura cutânea e a idade influem nos resultados. O parâmetro mais importante, sensível e de ocorrência mais precoce na STC é a redução da velocidade de condução sensitiva através do punho. Outros achados habituais são: diminuição da velocidade de condução motora e, em quadros mais avançados, perda de unidades motoras com presença de potenciais de desnervação na musculatura tenar. A ENMG tem um papel importante no diagnóstico diferencial da STC com a radiculopatia cervical e com polineuropatias periféricas, além de ser útil na avaliação e seguimento pós-operatórios.

\section{Diagnóstico diferencial}

Alguns distúrbios devem ser considerados no diagnóstico diferencial da STC além da história, avaliação neurológica e estudos de condução nervosa. A radiculopatia cervical é a desordem primária que pode ser confundida com STC. Devem ser incluídas no diagnóstico diferencial qualquer patologia que cursa com dor e alterações sensitivas nas mãos, incluindo a radiculopatia das raízes $\mathrm{C} 6 \mathrm{e}$ C7, a síndrome do desfiladeiro torácico, a compressão proximal do nervo mediano e a síndrome de De Quervain.

\section{Tratamento Conservador}

Existem diversas evidências sobre a eficácia da injeção de corticoide, imobilização por órteses e corticoterapia via oral. Intervenções pelos métodos de ultrassonografia, laser, diuréticos, vitaminoterapia B6, perda de peso são ainda duvidosos. Não existem indicações com comprovação científica, nem consensos na literatura sobre a estratégia a adotar.

\section{Injeção local de corticoide}

A ação é a diminuição do volume tenossinovial e um efeito direto sobre o nervo mediano. O principal risco é a lesão do nervo mediano, que pode ocasionar muito dor, com sensação de choque elétrico e risco de déficit neurológico e dores persistentes. Outro problema é o risco de ruptura do tendão.

Usa-se comumente um ponto de injeção de $4 \mathrm{~cm}$ proximal à prega de flexão do punho a meio caminho entre o tendão do palmar longo (PL) e o flexor ulnar do carpo (FUC), o qual é proporcional ao tamanho do eixo do quarto dedo. Posteriormente a antissepsia local, a agulha é colocada oblíqua e lentamente a $45 \circ$ do túnel do carpo. Não deve haver qualquer resistência anormal. Com o auxílio da outra mão verifica-se se a agulha não se localiza na região intratendínea e mobiliza os dedos passivamente. Em seguida injeta-se lentamente. Uma reação dolorosa e transitória pode ocorrer dentro de horas após a injeção.

A injeção entre o flexor radial do carpo (FRC) e o PL é motivo de lesão ao nervo mediano, dada a localização do nervo. Dreano et al a fizeram no lado ulnar do PL. Dubert e Racasan relataram as medidas do nervo mediano com os tendões do PL, do FRC e do $F U C, 1 \mathrm{~cm}$ a montante da prega de flexão do punho, e apontaram uma zona de risco situada a $1 \mathrm{~cm}$ de cada lado do tendão PL. Eles recomendam injetar através do FRC em um ângulo de 45॰ distal e 45॰ ulnar. Não há diferença entre uma injeção de 1 a $4 \mathrm{~cm}$ proximal e uma injeção na prega de flexão do punho.

O alívio é observado após alguns dias a 
duas/três semanas da aplicação. A injeção de corticosteroides no local tem uma eficácia significativamente maior do que a injeção de placebo em um mês e mais duradoura do que a corticoterapia via oral em dois a três meses. Após a injeção de corticoide local é observado um alívio temporário, o que é um bom prognóstico para o tratamento cirúrgico. Duas injeções não têm mais eficácia do que uma só. Mais de três injeções não são recomendadas. O tempo mínimo aconselhado entre duas injeções é de um mês. Diabetes mellitus é uma contraindicação. Na SCC intermitente não deficitária, foi obtida 93,7\% de melhoria clínica e na eletroneuromiografia (ENMG) em três meses, 79\% em 16 meses, com 50\% de normalização ENMG. Gelbermann et al., em uma série de pacientes com ou sem déficit, tratados por infiltração e órtese por três semanas seguidas entre seis e 26 meses, encontraram apenas $22 \%$ de ausência dos sintomas no recuo máximo. Os parâmetros de um bom prognóstico são: sintomas por menos de um ano e ausência de déficit motor ou sensorial.

\section{Órtese de imobilização noturna com o punho em posição neutra}

Foi comprovado que a pressão no túnel do carpo aumenta com a extensão e a flexão do punho. A posição do punho com a tala deve estar em estrita localização neutra rara para diminuir a pressão intracanalicular. A órtese sob medida pode ser feita e adaptada de acordo com as patologias coexistentes (e.g. rizartrose). O desfecho desse tratamento parece no máximo equivalente à injeção de corticosteroides. Stutzmann et al encontraram alívio na STC moderada em $81 \%$ dos casos em três anos. $\mathrm{O}$ tempo de tratamento é de três semanas a três meses. A órtese pode ser associada com a infiltração.

\section{Modificação das medidas mecânicas e ergonômicas}

A diminuição, pelo menos temporária, da atividade permite muitas vezes um alívio, particularmente no caso de STC nos homens após excesso de trabalho manual. Em teclados ergonômicos, nenhuma mudança significativa foi encontrada em termos de melhoria dos sintomas e das anomalias à ENMG com teclados tradicionais dos pacientes com STC provada.

\section{Tratamento cirúrgico}

O objetivo é obter a redução da pressão intratúnel pelo aumento do volume do túnel do carpo, por causa da secção do retináculo dos flexores (RF). O procedimento é feito sob anestesia locorregional ou local, em princípio em regime ambulatorial, frequentemente sob torniquete. Os métodos são, em princípio, unilaterais.

Deve-se salientar para não colocar o nervo mediano na extensão da cicatriz da incisão para que assim possa minimizar as aderências epineurais pósoperatórias.

\section{Anestesia e cirurgia do túnel do carpo}

A cirurgia do túnel do carpo pode ser realizada sob anestesia local, locorregional ou geral. Em caso de anestesia local, a tolerância ao torniquete é o principal fator limitante. Quanto à anestesia locorregional pelo bloqueio dos troncos mediano, ulnar e musculocutâneo, a tolerância dos bloqueios parece pior no punho do que no canal braquial.

A infiltração do túnel do carpo ligada ao tecido subcutâneo no nível da incisão alivia mais o paciente durante e no pós-operatório do que a infiltração subcutânea somente. O torniquete é inflado após a injeção. A epinefrina evitaria o torniquete.

Para a cirurgia endoscópica, bloqueios tronculares distais mediano, ulnar e musculocutâneo $6 \mathrm{~cm}$ a montante da prega de flexão do punho podem prevenir a infiltração de partes moles e interferir consideravelmente na endoscopia. Segundo Delaunay e Chelly, 19 depois de 10 minutos, $9 \%$ e 32\% dos pacientes necessitaram de anestesia adicional no nível dos nervos mediano e ulnar. Nenhum déficit neurológico parcial ou total foi demonstrado no pósoperatório.

\section{Técnica aberta}

É a mais antiga. A incisão de $3-4 \mathrm{~cm}$ se estende da prega de flexão do punho, no prolongamento da borda radial do quarto dedo, à linha cardinal de Kaplan. A camada de gordura da região hipotênar é interposta no fim da cirurgia entre a pele e o RF. Em seguida, a aponeurose palmar média é incisada radialmente. A dissecção subcutânea, para preservar os ramos sensitivos suscetíveis de criar dores pós-operatórias, não demonstrou a sua superioridade em relação a uma incisão com um bisturi diretamente no RF. A 
hemostasia por coagulação bipolar é uma demanda. $\mathrm{O}$ RF é exposto com afastadores. As pinças de dissecação identificam o hâmulo do hamato. O RF é então incisado na sua parte média no lado ulnar do eixo no quarto dedo e deixa uma margem ulnar para limitar a subluxação dos flexores. A secção do RF continua precavidamente distal até a arcada palmar superficial e a anastomose mediana-ulnar. Proximalmente, o RF é separado profundamente da sinóvia dos flexores com tesouras de dissecação. 0 conteúdo do túnel do carpo é verificado: anomalia muscular, aspecto da sinóvia. Para se ver o nervo mediano, deve ser levantada cuidadosamente a borda radial do RF com um afastador. O nervo mediano é o componente mais superficial e radial. 0 fechamento da pele é então feito.

\section{CONSIDERAÇÕES FINAIS}

A STC representa a mais frequente das mononeuropatias compressivas e é um dos transtornos dos membros superiores que mais geram incapacidades. Embora não exista um padrãoouro para diagnóstico, diversos testes são adotados e podem garantir credibilidade. O tratamento conservador pode ser feito por meio da injeção de corticoide, imobilização por órteses e corticoterapia via oral. No entanto, podem ser adotadas outras técnicas, embora estas não tenham eficácia comprovada.

\section{REFERÊNCIAS}

1. DE OLIVEIRAFILHO, J. R.; DE OLIVEIRA, A. C. R. Síndrome do túnel do carpo na esfera trabalhistaRevista Brasileira de Medicina do Trabalho, 2017.

2. HUISSTEDE, B. M. et al. Carpal Tunnel Syndrome: Effectiveness of Physical Therapy and Electrophysical Modalities. An Updated Systematic Review of Randomized Controlled TrialsArchives of Physical Medicine and RehabilitationElsevier Inc, , 2018.

3. CHAMMAS, M. et al. Carpal tunnel syndrome - Part i (anatomy, physiology, etiology and diagnosis). Revista Brasileira de Ortopedia, v. 49, n. 5, p. 429-436, 2014 a.

4. MARTINS, R. S. Compressão Do Nervo Mediano No Punho (Síndrome Do Túnel Do Carpo). 2015.

5. PADUA, L. et al. Carpal tunnel syndrome: clinical features, diagnosis, and management. The Lancet Neurology, v. 15, n. 12, p. 1273-1284, 2016.

6. PALUMBO, C. F.; SZABO, R. M. Examination of patients for carpal tunnel syndrome. Hand Clinics, v. 18, n. 2, p. 269-277, 2005.

7. CHAMMAS, M. et al. Carpal tunnel syndrome - Part II (treatment). Revista Brasileira de Ortopedia, v. 49, n. 5, p. 437-445, 2014b 